\title{
Serum IL-6 Level in Breast Cancer Surgery: Evaluating the Addition of Hydrocortisone to Two Anesthetic Regimens
}

\author{
Sherif Abdelhamid ${ }^{1, *}$, Ahmed Talha ${ }^{2}$, Salwa Hamdy ${ }^{3}$, Ashraf Arafat Abdelhalim ${ }^{4}$ and \\ Mohamed Elakany ${ }^{1}$
}

${ }^{I}$ Department of Anesthesia, Medical Research Institute, Alexandria University, Alexandria, Egypt

${ }^{2}$ Department of Surgery, Medical Research Institute, Alexandria University, Alexandria, Egypt

${ }^{3}$ Chemical Pathology, Medical Research Institute, Alexandria University, Alexandria, Egypt

${ }^{4}$ Department of Anesthesia, Alexandria University, Alexandria, Egypt

\begin{abstract}
Background: Interleukin (IL-6) and C-reactive protein (CRP) are found to be elevated in various inflammatory and malignant diseases and their levels are found to correlate with the extent of the disease. We evaluated the role of adding hydrocortisone to two different anesthetic regimens, on the level of IL-6, CRP and cortisol levels following breast cancer surgery.

Patients and Methods: In this prospective, randomized, controlled trial, 124 ASA I-II, female patients, aged 30-50 years, undergoing conservative breast cancer surgery were randomly assigned to one of four equal groups receiving either standard general anesthesia and two doses of hydrocortisone (Group $\mathrm{GH}, \mathrm{n}=31$ ), thoracic paravertebral block and two doses of hydrocortisone (Group PH, n=31), standard general anesthesia with no hydrocortisone (Group $\mathrm{G}$, $\mathrm{n}=31$ ), or thoracic paravertebral block with no hydrocortisone (Group P, n=31). IL-6 was measured at three time points: before operation, 6 and 12 hours postoperatively. CRP and cortisol were measured preoperatively and 6 hours postoperatively.

Results: On comparing group $\mathrm{PH}$ and GH, there was significant decrease in IL-6 level in group PH compared to group GH at 6 hour $(122.1 \pm 21.2 v s 135.8 \pm 29.8 \mathrm{pg} / \mathrm{dl})$, but insignificant difference at 24 hours $(107.9 \pm 21.6 v s 106.8 \pm 15.9 \mathrm{pg} / \mathrm{dl})$. CRP showed significant decrease in the postoperative reading in group $\mathrm{PH}$ compared to group GH $(1.63 \pm 0.32 v \mathrm{~s}$ $1.91 \pm 0.43 \mathrm{mg} / \mathrm{l})$, and also group PH showed significant decrease compared to the control group P (1.63 \pm 0.32 vs $2.2 \pm 0.54)$.

Conclusion: addition of hydrocortisone to general anesthesia or thoracic paravertebral block attenuated production of IL-6 and CRP levels significantly postoperatively compared to either anesthetic regimen alone, but not the serum cortisol level, highlighting its role in modifying the stress response to surgery. However, the effect was more pronounced when combined with thoracic paravertebral block.
\end{abstract}

Keywords: Anesthetic, breast, cancer, hydrocortisone, IL-6, regimens.

\section{INTRODUCTION}

The cytokines are low-molecular-weight heterogenous proteins which include interleukins and interferons. The main cytokines released are interleukin-1 (IL-1), tumor necrosis factor- $\alpha$ (TNF- $\alpha$ ) and Interleukin (IL-6) [1]. They have a major role in the inflammatory response to malignancy, trauma and surgery, inducing local and systemic effects which attempt to limit injury and seem to be directly involved in the symptomatology of sepsis, multiorgan failure and septic shock [2]. IL-6 is a sensitive, early marker of tissue damage, and the main proinflammatory cytokine responsible for inducing acute phase response $[1,3]$. It has a

*Address correspondence to this author at the Department of Anesthesia, Medical Research Institute, Alexandria University, Alexandria, Egypt;

E-mail:dr_shereif@hotmail.com major impact on outcome following surgery as its levels are increased in breast cancer patient. Excessive IL-6, both circulating and within the breast tumor microenvironment, is associated with poor clinical outcomes in breast cancer [4]. IL-6 stimulates secretion of C-reactive protein (CRP) from the liver, which is now considered to be an important biomarker for proinflammatory status in several diseases including cancer [5]. Both IL-6 and CRP are found to be elevated in various inflammatory and malignant diseases and their levels are found to correlate with the extent of the disease [6]. Serum IL-6 is released within minutes by blood leukocytes and constantly detected in the peripheral blood; therefore, the increase of IL-6 may reflect the magnitude of surgical trauma. By 24 to 36 hours postoperatively, the levels of IL-6 in the plasma decrease to preoperative values because of attenuated production [7-10]. It is believed that it stimulate auto and paracrine stimulation of tumor cell 
proliferation, in addition of being an independent prognostic marker of survival in metastatic breast cancer patients [11]. In literature, there are few researches focusing on the impact of hydrocortisone on cytokine levels in humans. In a prior study, the use of hydrocortisone led to significant decrease of the inflammatory response among patients undergoing bilateral total knee replacement indicated by measuring IL- 6 production [12]. This prospective, randomized, controlled study was performed to evaluate possible differences in the plasma inflammatory cytokine interleukin 6 (IL-6), the release of the stress hormones (cortisol), and C-reactive protein (CRP) by adding hydrocortisone to two different anesthetic regimens in a population of healthy female patients with cancer breast undergoing unilateral conservative breast cancer surgery.

\section{PATIENTS AND METHODS}

After obtaining Institutional Review Board approval (Trial number: PACTR201304000509378) and written informed consent, this prospective, randomized, controlled study was conducted at Medical Research Institute Hospital, Alexandria, Egypt in the period from April 2013 to February 2014. The study enrolled 124 female patients, ASA physical status I or II aged 30 to 50 years, with cancer breast scheduled for unilateral conservative breast cancer surgery.

Patients with endocrine or metabolic disorders, diabetes, morbid obesity (Body Mass Index $>40 \mathrm{~kg} / \mathrm{m}^{2}$ or $35 \mathrm{~kg} / \mathrm{m}^{2}$ with co-morbidity), history of CNS diseases, known allergy to bupivacaine or any contraindication to paravertebral block, pregnancy, lactation, taking steroid medications and patients under current or recent medication affecting the sympathetic response or the hormonal secretion were excluded from the study.

All patients were subjected to a standard pre-operative evaluation. The selected patients were randomly allocated to one of the four equal groups by using sealed, opaque envelopes to receive standard general anesthesia and two doses of hydrocortisone (Group $\mathrm{GH}, \mathrm{n}=31$ ), thoracic paravertebral block and two doses of hydrocortisone (Group $\mathrm{PH}, \mathrm{n}=31)$, standard general anesthesia with no hydrocortisone (Group G, $\mathrm{n}=31$ ), or thoracic paravertebral block with no hydrocortisone (Group P, $\mathrm{n}=31$ ).

In group (GH), on arrival at the operating theatre, routine standard monitoring was used for all patients, after preoxygenation using 100\% Oxygen for 3 minutes, all patients received standard anesthetic techniques; anesthesia was induced by fentanyl $1.5 \mu \mathrm{g} / \mathrm{kg}$, and propofol $2 \mathrm{mg} / \mathrm{kg}$ followed by the administration of cisatracurium $0.15 \mathrm{mg} / \mathrm{kg}$ to facilitate orotracheal intubation. Anesthesia was maintained with isoflurane $1-1.5 \%$ in a mixture of air in oxygen $(60 \%: 40 \%)$, and patients received intermittent doses of fentanyl and cisatracurium. All patients received hydrocortisone $100 \mathrm{mg}$ intravenously at induction and the same dose was repeated 2 hours later.

Patients in Group (PH) were sedated during performance of thoracic paravertebral block (TPVB) with propofol infusion in a dose of $100 \mathrm{mcg} / \mathrm{kg} / \mathrm{min}$ using a syringe pump (Life Care5000 Infusion Set, Abbott, Ireland). Thoracic paravertebral blocks were then performed as described by
Katz [13]. Paravertebral injections were performed with the patient in lateral position (surgical side facing upward). Spinous processes of T3 to T6 were identified and a mark was taken corresponding to $2.5 \mathrm{~cm}$ lateral to them. After aseptic preparation of the skin, these points were infiltrated with lidocaine1\% 1-2 ml. An 18-gauge Epidural Tuohy needle was inserted perpendicular to the skin at $\mathrm{T} 4$ at the corresponding mark, when the tip of the needle touched the corresponding transverse process, the needle was withdrawn and redirected cephalad to slide over the transverse process to reach a depth of $4 \mathrm{~cm}$ as a maximum, piercing the superior costotransverse ligament and advanced into the paravertebral space. A loss of resistance to saline was usually encountered to confirm the space at this depth. After negative aspiration of blood, air or cerebrospinal fluid, $30 \mathrm{ml}$ of bupivacaine $0.5 \%$ was injected; adequate block was confirmed by loss of temperature sensation over appropriate dermatomes, and by testing pinprick sensation in the surgical field before incision. All patients were contacted verbally and routine standard monitoring was used for all patients. After assuring adequate anesthesia and the patient was vitally stable, without any manifestations of local anesthetic toxicity, the surgery started. All patients received hydrocortisone $100 \mathrm{mg}$ at start of block and the same dose was repeated two hours later. Two senior consultants performed the TPVBs to minimize variation in the technique.

Patients in group (G) received the same standard anesthetic techniques as group $(\mathrm{GH})$ without administration of Hydrocortisone and this group was served as control group.

Patients in group (P) received the same thoracic paravertebral block technique as group (P) without administration of Hydrocortisone and this group was served as control group.

Postoperative pain scores in the first 24 hours were always below or equal 3 on visual analogue scale (VAS) in all studied groups. Infusion of $0.125 \%$ buipivacaine in the paravertebral groups, while using $30 \mathrm{mg}$ ketorolac/ 8 hours IV. in the general anesthesia groups and nalbuphine of $2 \mathrm{mg}$ IV. As a rescue analgesic, to maintain VAS of $\leq 3$.

Venous blood samples were collected peripherally, from an antecubital vein of the arm contralateral to the surgery, using a small cannula. For each patient in all groups, peripheral blood samples for measuring IL-6 were collected at three time points: before operation, six hour after the end of the procedure, and twenty four hours after the procedure. IL-6 was measured in serum samples by enzyme linked immunosorbent assay using AviBion Human IL-6 ELISA KIT, FINLAND, The assay employed an antibody specific for human IL-6 coated on a 96-well plate. IL-6 in samples is captured by the antibody immobilized to the wells and by a biotinylated IL-6 specific detection antibody. After washing away unbound biotinylated antibody, HRP-conjugated streptavidin and TMB substrate solution were added to the wells resulting in color development proportional to the amount of IL- 6 bound. The intensity of the color was measured at $450 \mathrm{~nm}$. The mean of reagent blank absorbance values were calculated and substracted from all test well (standard and samples). A calculated result against standard curve was drawn [14]. Serum and plasma samples were 
isolated from whole blood by centrifugation according to standard protocols.

CRP and cortisol were measured preoperatively and 6 hours postoperatively. Cortisol was measured in serum samples by electrochemiluminescence immunoassay technique (ECLIA) on Cobas e immunoassay analyser based on competition test principle using a polyclonal antibody which is specifically directed against cortisol. Endogenous cortisol in the sample which has been liberated from binding protein with danazol competes with exogenous cortisol derivative in the test which has been labeled with ruthenium comlex for the binding sites on the biotinylated antibody. Results were determined via a calibration curve which is instrument-specifically generated by 2-point calibration and a master curve provided via the reagent barcode [15].

\section{Statistical Analysis}

Statistical analysis was done by SPSS version 18.0 for analyzing the collected data. The following statistical measures were used:

- Descriptive statistics including range, mean, and standard deviation were used to describe different characteristics.

- Kolmogorov - Smirnov test was used to examine the normality of data distribution.

- Univariate analyses including: t-test and paired t-test were used to test the significance of results of quantitative variables. Moreover, Chi-Square test, Monte Carlo test, were used to test the significance of results of qualitative variables.
- The significance of the results was at the 5\% level of significance.

\section{RESULTS}

One hundred thirty seven patients on the surgical list were identified as possible participants. Of these, thirteen were not eligible due to exclusion criteria. The remaining 124 patients fulfilled all criteria, and were allocated to participate in the study with no patient drop outs (Fig. 1). All four groups were comparable with respect to age, body mass index (BMI), duration of operation and American Society of Anesthesiologists's classification (ASA) (P>0.05, Table 1).

All groups showed insignificant difference in the baseline value of IL-6 between groups ( $\mathrm{P}>0.05$, Table 2, Fig. 2) and each group showed significant increase of IL-6 level at 6 and 24 hours postoperatively, compared to its baseline levels ( $\mathrm{P}$ $<0.05$, Table 2, Fig. 2). All groups showed significant decrease in IL-6 values at 24 hours compared to 6 hours postoperatively ( $\mathrm{P}<0.05$, Table 2 , Fig. 2). On comparing group $\mathrm{PH}$ and $\mathrm{GH}$, there was significant decrease in IL-6 level in group $\mathrm{PH}$ compared to group $\mathrm{GH}$ at 6 hour (122.1 \pm 21.2 vs $135.8 \pm 29.8 \mathrm{pg} / \mathrm{dl})$, but insignificant difference at 24 hours $(107.9 \pm 21.6$ vs $106.8 \pm 15.9 \mathrm{pg} / \mathrm{dl})$. However, there was significant difference in the IL- 6 values at 6 and 24 hours between both; group HG and its control (group G) $(135.8 \pm 29.8$ vs $158.1 \pm 40.8 \mathrm{pg} / \mathrm{dl})$, at 6 hours, and 24 hours (107.6 \pm 21.9 vs $147.7 \pm 39.9 \mathrm{pg} / \mathrm{dl})$, and group HP and its control (Group P) at 6 hours ( $122.1 \pm 21.2$ vs $156.9 \pm 39.6$ $\mathrm{pg} / \mathrm{dl})$, and 24 hours $(106.8 \pm 15.9$ vs $146.9 \pm 39.3 \mathrm{pg} / \mathrm{dl})$.

All four groups showed significant increase in cortisol level in the postoperative period compared to baseline reading $(9.41 \pm 1.40$ vs $20.11 \pm 1.72,9.52 \pm 1.4$ vs $120.60 \pm 1.61$,

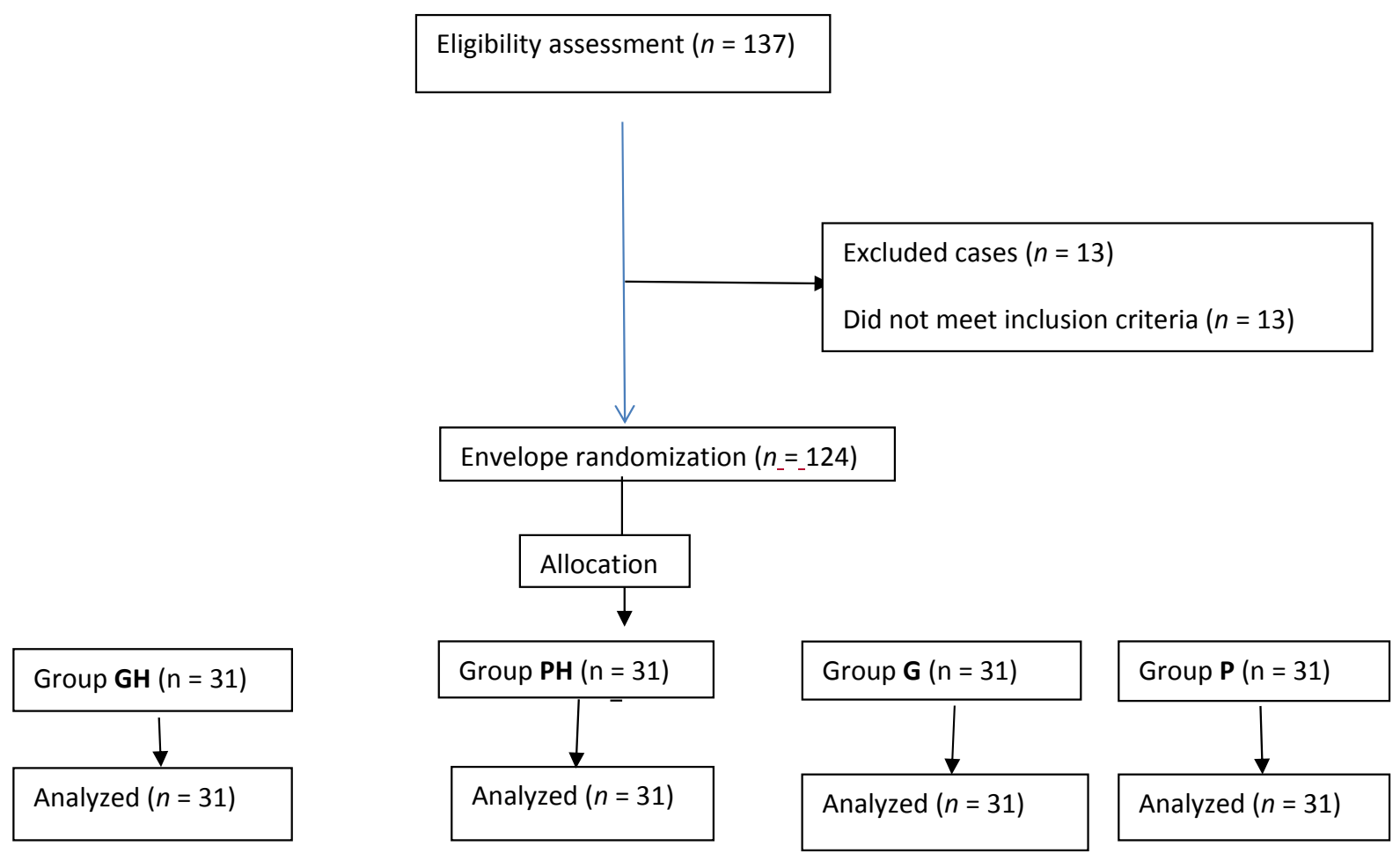

Fig. (1). Flow chart of the study. 
$9.54 \pm 1.6$ vs $20.93 \pm 1.74,9.50 \pm 1.5$ vs $20.72 \pm 1.60$ in groups $\mathrm{GH}, \mathrm{PH}, \mathrm{G}$ and $\mathrm{P}$ respectively $(\mathrm{P}<0.05$, Table 3 ), however, the difference between groups was statistically insignificant $(\mathrm{P}>0.05$, Table 3).

All four groups showed significant increase in CRP postoperatively compared to baseline value $(\mathrm{P}<0.05$,
Table 4), however, the CRP value was significantly less in group $\mathrm{PH}$ compared to group $\mathrm{GH}$ postoperatively $(1.63 \pm 0.32$ vs $1.91 \pm 0.43 \mathrm{mg} / 1$, respectively, $\mathrm{P}<0.05$, Table 4). The CRP values was significantly less in both group $\mathrm{PH}$ and group $\mathrm{GH}$ compared to their controls; $(1.91 \pm 0.43$ vs $2.23 \pm 0.40 \mathrm{mg} / \mathrm{l})$ and (1.63 \pm 0.32 vs $2.2 \pm 0.54)$ respectively, $\mathrm{P}<0.05$, Table 4).

Table 1. Patients characteristics.

\begin{tabular}{|c|c|c|c|c|}
\hline Personal characteristics & $\begin{array}{c}\text { Group (GH) } \\
\quad(n=31)\end{array}$ & $\begin{array}{c}\text { Group (PH) } \\
\quad(n=31)\end{array}$ & $\begin{array}{c}\text { Control (G) } \\
(n=31)\end{array}$ & $\begin{array}{c}\text { Control (P) } \\
(n=31)\end{array}$ \\
\hline \multicolumn{5}{|l|}{ Age (years) } \\
\hline Min-Max & $30-49$ & $33-48$ & $31-45$ & $34-50$ \\
\hline Mean \pm SD & $41.1 \pm 3.2$ & $42.6 \pm 2.9$ & $39.8 \pm 2.8$ & $44.5 \pm 5.1$ \\
\hline \multicolumn{5}{|l|}{ BMI $\left(\mathrm{Kg} / \mathrm{m}^{2}\right)$} \\
\hline Min-Max & $26.6-34.4$ & $28.1-35.8$ & $27.4-34.9$ & $26.2-35.4$ \\
\hline Mean \pm SD & $31.2 \pm 4.7$ & $32.6 \pm 3.9$ & $31.8 \pm 2.7$ & $32.1 \pm 4.5$ \\
\hline \multicolumn{5}{|l|}{ Duration of surgery (min) } \\
\hline Min-Max & $70-90$ & $70-85$ & $65-90$ & $70-95$ \\
\hline ASA I & $11(35.5 \%)$ & $10(32.3 \%)$ & $12(38.7 \%)$ & $7(22.6 \%)$ \\
\hline ASA II & $20(64.5 \%)$ & $21(67.7 \%)$ & $19(61.3 \%)$ & $24(77.4 \%)$ \\
\hline
\end{tabular}

ASA $=$ American Society of Anesthesiologists. Values are presented as means (SD), or number of patients (n) and percentages (\%).

Table 2. Interleukin- 6 measured pre and postoperatively among the studied groups.

\begin{tabular}{|c|c|c|c|c|c|c|c|}
\hline Interleukin 6 (pg/dl) & $\begin{array}{c}\text { Group (GH) } \\
(\mathbf{n}=\mathbf{3 1})\end{array}$ & $\begin{array}{c}\text { Group (PH) } \\
(\mathbf{n}=\mathbf{3 1})\end{array}$ & $\begin{array}{c}\text { Control (G) } \\
\quad(n=31)\end{array}$ & $\begin{array}{c}\text { Control (P) } \\
\quad(n=31)\end{array}$ & Sig 1 & Sig 2 & Sig 3 \\
\hline \multicolumn{8}{|l|}{ Preoperative } \\
\hline Min-Max & $35-130$ & $45-130$ & $53-120$ & $50-120$ & $\mathrm{t}=0.711$ & $\mathrm{t}=0.393$ & $\mathrm{t}=0.42$ \\
\hline Mean \pm SD & $86.3 \pm 20.9$ & $89.8 \pm 18.4$ & $88.0 \pm 13.9$ & $87.7 \pm 13.9$ & $\mathrm{P}=0.48$ & $\mathrm{P}=0.696$ & $\mathrm{P}=0.676$ \\
\hline Min-Max & $80-200$ & $70-160$ & $100-280$ & $100-280$ & $\mathrm{t}=2.134$ & $\mathrm{t}=2.453$ & $\mathrm{t}=4.461$ \\
\hline Mean \pm SD & $135.8 \pm 29.8$ & $122.1 \pm 21.2$ & $158.1 \pm 40.8$ & $156.9 \pm 39.6$ & $\mathrm{P}=0.037^{*}$ & $\mathrm{P}=0.017^{*}$ & $\mathrm{P}<0.0001^{*}$ \\
\hline \multicolumn{8}{|l|}{24 hours post-operative } \\
\hline Min-Max & $55-150$ & $80-140$ & $95-260$ & $95-260$ & $\mathrm{t}=0.172$ & $\mathrm{t}=4.912$ & $\mathrm{t}=5.46$ \\
\hline Sig (Pre/24 hrs Postoperative) & {$\left[\mathrm{P}<0.0001^{*}\right]$} & {$\left[\mathrm{P}<0.0001^{*}\right]$} & {$\left[\mathrm{P}<0.0001^{*}\right]$} & {$\left[\mathrm{P}<0.0001^{*}\right]$} & & & \\
\hline $\begin{array}{l}\text { Sig (Post } 6 \text { hrs } / 24 \text { hrs } \\
\text { Postoperative) }\end{array}$ & {$\left[\mathrm{P}<0.0001^{*}\right]$} & {$\left[\mathrm{P}<0.0001^{*}\right]$} & {$\left[\mathrm{P}<0.0001^{*}\right]$} & {$\left[\mathrm{P}<0.0001^{*}\right]$} & & & \\
\hline
\end{tabular}

Sig1: Significance between Group (GH) and Group (PH)

Sig2: Significance between Group $(\mathrm{GH})$ and Control $(\mathrm{G})$ Group

Sig3: Significance between Group (PH) and Control (P) Group

t: $t$-test [P]: $\mathrm{P}$ for Paired t-test *significant at $\mathrm{P} \leq 0.05$ 


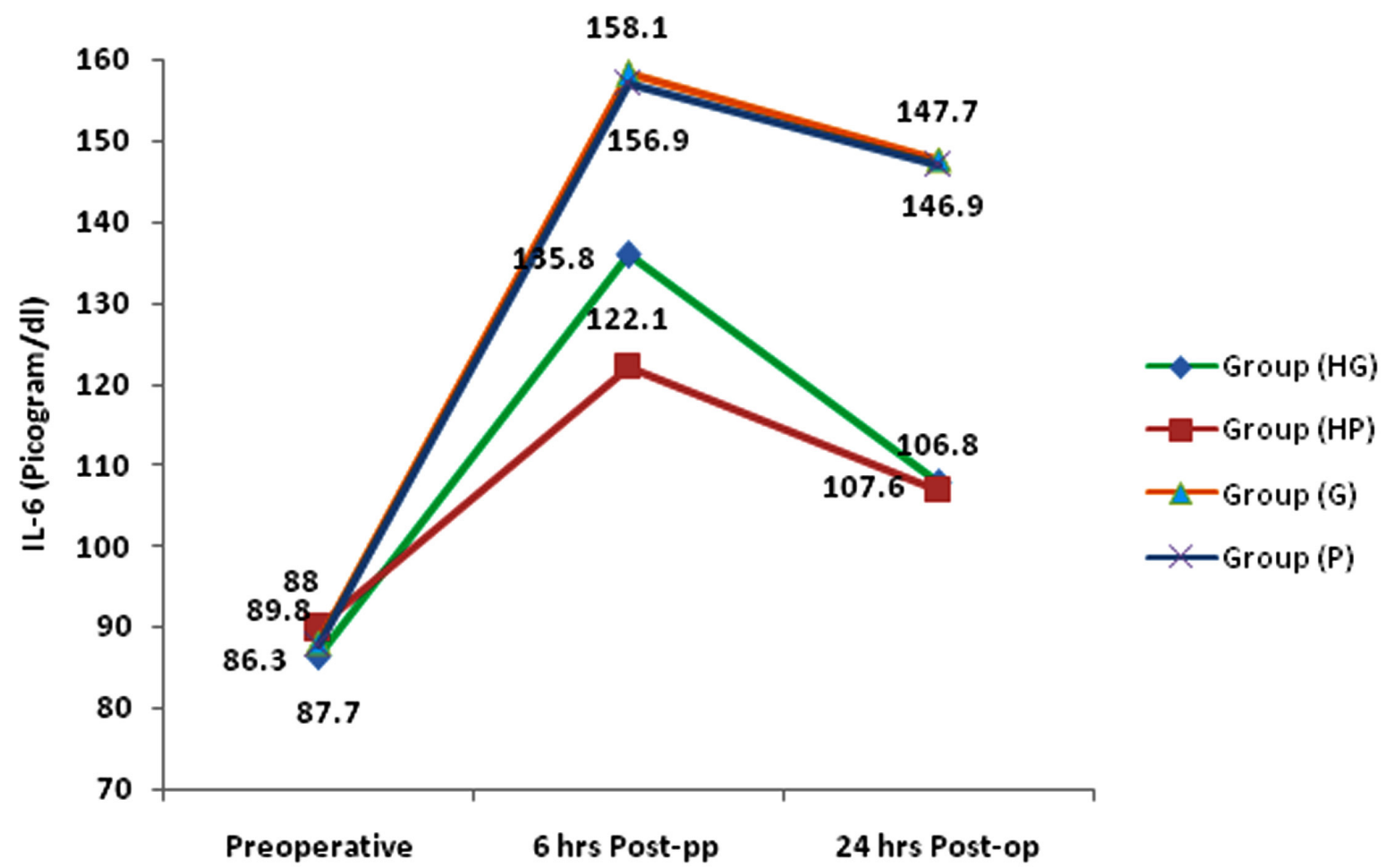

Fig. (2). Interleukin- 6 measured pre and postoperatively among the studied groups.

Table 3. Serum cortisol level measured pre and postoperatively among the studied groups.

\begin{tabular}{|c|c|c|c|c|}
\hline Serum cortisol level & $\begin{array}{c}\text { Group (GH) } \\
(\mathbf{n}=\mathbf{3 1})\end{array}$ & $\begin{array}{c}\text { Group (PH) } \\
(\mathbf{n}=\mathbf{3 3})\end{array}$ & $\begin{array}{c}\text { Control (G) } \\
(\mathbf{n}=\mathbf{3 1})\end{array}$ & $\begin{array}{c}\text { Control (P) } \\
(\mathrm{n}=\mathbf{3 1})\end{array}$ \\
\hline \multicolumn{5}{|l|}{ Preoperative } \\
\hline Min-Max & $9.1-10.0$ & $9.3-10.1$ & $8.9-10.2$ & $8.8-10.0$ \\
\hline Mean \pm SD & $9.41 \pm 1.40$ & $9.52 \pm 1.41$ & $9.54 \pm 1.6$ & $9.50 \pm 1.5$ \\
\hline \multicolumn{5}{|l|}{ Post-operative } \\
\hline Min-Max & $18.8-22.0$ & $18.5-23.4$ & $19.0-22.4$ & $18.1-22.3$ \\
\hline Mean \pm SD & $20.11 \pm 1.72 *$ & $20.60 \pm 1.61^{*}$ & $20.93 \pm 1.74 *$ & $20.72 \pm 1.60^{*}$ \\
\hline
\end{tabular}

$* \mathrm{P}<0.05$ significant compared to baseline.

Table 4. CRP level measured pre and postoperatively among the studied groups.

\begin{tabular}{|c|c|c|c|c|}
\hline $\mathrm{CRP}(\mathrm{mg} / \mathrm{L})$ & $\begin{array}{c}\text { Group (GH) } \\
\quad(\mathbf{n}=\mathbf{3 1})\end{array}$ & $\begin{array}{c}\text { Group (PH) } \\
\quad(\mathbf{n}=\mathbf{3 3})\end{array}$ & $\begin{array}{c}\text { Control (G) } \\
(\mathbf{n}=\mathbf{3 1})\end{array}$ & $\begin{array}{c}\text { Control (P) } \\
\quad(n=31)\end{array}$ \\
\hline \multicolumn{5}{|l|}{ Preoperative } \\
\hline Min-Max & $0.7-1.8$ & $0.8-1.9$ & $0.9-1.8$ & $0.6-1.9$ \\
\hline Mean \pm SD & $1.24 \pm 0.31$ & $1.32 \pm 0.37$ & $1.21 \pm 0.30$ & $1.23 \pm 0.44$ \\
\hline Min-Max & $1.2-3.0$ & $1.2-2.6$ & $1.8-3.2$ & $1.8-3.4$ \\
\hline Mean \pm SD & $1.91 \pm 0.43 *$ & $1.63 \pm 0.32 * \dagger$ & $2.23 \pm 0.40^{*}$ & $2.2 \pm 0.54 *$ \\
\hline
\end{tabular}

* $\mathrm{P}<0.05$ significant compared to baseline, $\dagger \mathrm{P}=0.001$ significant compared to group $\mathrm{GH}$,

$\ddagger \mathrm{P}<0.0001$ significant compared to group $\mathrm{G}, \quad \mathrm{P}<0.0001$ significant compared to group $\mathrm{P}$. 


\section{DISCUSSION}

This prospective, randomized, controlled study revealed that the addition of two doses of hydrocortisone to either general anesthesia or thoracic paravertebral block attenuated production of IL-6 significantly at 6 and 24 hours postoperatively compared to control groups, demonstrating the role of hydrocortisone in reducing the IL-6 level. In animal models, Lodge et al. [16] showed that the use of glucocorticoids can reduce the interleukins 6 and 8, tumor necrosis factor-(TNF- $\alpha$ ) and increase anti-inflammatory cytokines such as IL-10, IL-4.

Elysee et al. [12] reported that, the use of hydrocortisone $(100 \mathrm{mg})$ at 2 doses $8 \mathrm{hrs}$ apart significantly decreased the inflammatory response in patients undergoing bilateral total knee replacement as the levels of IL- 6 were $40 \%$ lower in the study group compared to placebo group. Moreover, the range of motion gained on discharge was also greatest in the study group. In another study, it has been suggested that combined preoperative and intraoperative steroid administration attenuates the inflammatory response more effectively than intraoperative steroid administration alone [17].

In our study, the baseline level of IL-6 was elevated in all groups. Hussien MZ et al. [18] in their study showed that the baseline IL-6 level is highly increased in breast cancer patients, and that serum levels of IL-6 (mean $=111.38 \mathrm{pg} / \mathrm{ml}$ ) was significantly increased in breast cancer patients as compared to controls (mean $1.75 \mathrm{pg} / \mathrm{ml}$ ). Addionally, Dethlefsen et al. [19] illustrated in their study that high circulating IL-6 levels are correlated with a poor prognosis in breast cancer patients. Surgical stress is known to induce an increase in serum levels of IL-6. However, different regimens of anesthesia are associated with differences in cytokine secretion pattern.

A combination of hydrocortisone and general anesthesia provided significantly less attenuation of production of IL-6 compared to combination of hydrocortisone with thoracic paravertebral block at 6 hours but not 24 hours postoperatively. These results indicate that TPVB seems to better attenuate the production of IL- 6 compared to general anesthesia. However, in the current study, TPVB was not continued postoperatively by using a catheter technique in the paravertebral space. This may explain insignificant differences between groups 24-h post-operatively. Many anesthetic techniques are used to decrease immune responses to surgeries, and it has been reported that the stress response to surgery, is attenuated by regional anesthesia, including paravertebral anesthesia by blocking pain pathways [20-22].

The results of the current study supported the findings reached by Cuellar et al. [23] who measured the proinflammatory cytokines in subjects undergoing laparoscopic cholecystectomy, receiving either regional or general anesthesia, comparing the 2 groups, they argued that proinflammatory cytokines was significantly higher in the general anesthesia group. In another study by, Hadimioglu et al. [24] they showed that IL-6 levels increased significantly at all the measured times compared with the baselines level in both general anesthesia group, and combined epidural with general anesthesia group. On comparing the 2 groups, they observed that the increase was greater in the general anesthesia compared with the combined group at all measured times.

Experimental studies in rats showed that surgical stress is attenuated better by the addition of spinal blockade to general halothane anesthesia than by general anesthesia alone and that, consequently, natural killer cell function is better preserved and markedly attenuates the promotion of metastasis by surgery [25]. A retrospective analysis of 129 patients undergoing mastectomy and axillary lymph node dissection for breast cancer suggested a lower risk for cancer recurrence or metastasis during the initial years of follow-up in patients having surgery with paravertebral block combined with a general anesthesia compared with patients with general anesthesia alone [26].

Our study showed that the postoperative increase of C-reactive protein concentrations was significantly less with combination of hydrocortisone with thoracic paravertebral block compared to combination of hydrocortisone and general anesthesia. Moreover, addition of hydrocortisone to either group provided significantly less increase compared to control groups highlighting that addition of hydrocortisone to anesthetic regimens could possibly decrease stress response markers which was more pronounced when added to thoracic paravertebral block. This result confirms previous clinical data, O'Riain et al. [21] showed that CRP as a marker of stress response were reduced in general anesthesia-paravertebral block group for breast cancer surgery compared to general anesthesia alone group $(2.6 \pm 1.5$ vs $5.7 \pm 2.9 \mathrm{nmol} / \mathrm{L}$ ). In another study, Rodriguez et al. [27] showed that thoracic epidural anesthesia significantly attenuated the CRP level.

Although, the postoperative serum cortisol level was significantly increased in all groups compared to baseline value, the difference between groups was insignificant. Conflicting results have been reported by Wedad et al. [28] who found that the serum cortisol level postoperatively was significantly lower in paravertebral group. In other study, Ibrahim et al. [29] found that the paravertebral group had significant lower values of postoperative serum cortisol compared to thoracic epidural group. In other report, Aggo et al. [30] compared plasma cortisol level in epidural versus general anesthesia groups, and found significant decrease in epidural group in all measured times. Our study is not quite similar with previous studies because of the variations in study design; the dosage, timing of hydrocortisone administration and timing of serum cortisol level measurement.

Limitations of the study include that; first, we measured only one inflammatory cytokine, future studies would benefit from assessments of more cytokines. Second, serum cortisol level would need more monitoring to trace the changes after I.V hydrocortisone injection. Third, we did not measure any clinical outcomes; therefore further clinical trials would be required to ascertain whether the differences in cytokine levels affect tumor recurrence, wound healing and patient survival. Finally, more studies on larger scale are warranted with possibly more doses of hydrocortisone. 


\section{CONCLUSION}

We found that of addition of hydrocortisone to either general anesthesia or thoracic paravertebral block attenuated production of IL-6 and CRP levels significantly postoperatively compared to either anesthetic regimen alone, but not the serum cortisol level, highlighting its role in modifying the stress response to surgery. However, the effect was more pronounced when combined with thoracic paravertebral block, it is possible that TPVB may offer advantages in terms of inflammatory effects compared to general anesthesia.

\section{CONFLICT OF INTEREST}

The authors confirm that this article content has no conflict of interest.

\section{ACKNOWLEDGEMENTS}

The authors are grateful to the staff members of operating room, Medical Research Institute Hospital, Alexandria University, Alexandria, Egypt.

\section{REFERENCES}

[1] Desborough JP. The stress response to trauma and surgery. $\mathrm{Br} \mathrm{J}$ Anaesth 2000; 85: 109-17.

[2] Sheeran P, Hall GM. Cytokines in anaesthesia. Br J Anaesth 1997; 78: 201-19.

[3] Helmy SA, Wahby MA, El-Nawaway M. The effect of anaesthesia and surgery on plasma cytokine production. Anaesthesia 1999; 54(8): 733-8.

[4] Bachelot T, Ray-Coquard I, Menetrier-Caux C, et al. Prognostic value of serum levels of interleukin 6 and of serum and plasma levels of vascular endothelial growth factor in hormone-refractory metastatic breast cancer patients. Br J Cancer 2003; 88: 1721-6.

[5] Erlinger TP, Platz EA, Rifai N, et al. C-reactive protein and the risk of incident colorectal cancer. JAMA 2004; 291: 585-90.

[6] Ravishankaran P, Karunanithi R. Clinical significance of preoperative serum interleukin-6 and C-reactive protein level in breast cancer patients. World J Surg Oncol 2011; 9: 18.

[7] Holzheimer RG, Steinmetz W. Local and systemic concentrations of proand anti-inflammatory cytokines in human wounds. Eur $\mathrm{J}$ Med Res 2000; 5(8): 347-55.

[8] Notarnicola A, Moretti L, Tafuri S, et al. Postoperative pain monitor after total knee replacement. Musculoskelet Surg 2011; 95(1): 19-24.

[9] Pandazi A, Kapota E, Matsota P, et al. Preincisional versus postincisional administration of parecoxib in colorectal surgery: effect on postoperative pain control and cytokine response. A randomized clinical trial. World J Surg 2010; 34(10): 2463-9.

[10] Lin E, Calvano SE, Lowry SF. Inflammatory cytokines and cell response in surgery. Surgery 2000; 127(2): 117-26.

[11] Salgado R, Junius S, Benoy I, et al. Circulating IL-6 predicts survival in patients with metastatic breast cancer. Int $\mathrm{J}$ Cancer 2003; 103: 642-6.
[12] Elysee J, Kethy M, Lipnitsky, et al. Use of low dose steroids in decreasing cytokine release during bilateral total knee replacement. Reg Anesth Pain Med 2011; 36: 36-40.

[13] Katz J. Atlas of regional anesthesia. $2^{\text {nd }}$ ed. Norwalk: Appleton \& Lange 1994.

[14] Allen MJ1, Myer BJ, Khokher AM, et al. Pro-inflammatory cytokines and the pathogenesis of Gaucher's disease: increased release of interleukin-6 and interleukin-10. QJM 1997; 90(1): 1925.

[15] Prieto $\mathrm{B}$, Miguel $\mathrm{D}$, Costa $\mathrm{M}$, et al. New quantitative electrochemiluminescence method (ECLIA) for interleukin-6 (IL6) measurement. Clin Chem Lab Med 2010; 48(6): 835-8.

[16] Lodge AJ, Chai PJ, Daggett CW, et al. Methylprednisolone reduces the inflammatory response to cardiopulmonary bypass in neonatal piglets: Timing of dose is important. J Thoracic Cardiovasc Surg 1999; 117(3): 515-22.

[17] Schroeder VA, Pearl JM, Schwartz SM, et al. Combined steroid treatment for congenital heart surgery improves oxygen delivery and reduces postbypass inflammatory mediator expression. Circulation 2003; 107(22): 2823-8.

[18] Hussein MZ, Al Fikky A, Abdel Bar I, et al. Serum IL-6 and IL-12 levels in breast cancer patients. Egypt J Immunol 2004; 11(2): 16570.

[19] Dethlefsen C, Højfeldt G, Hojman P. High circulating IL-6 levels are correlated with a poor prognosis in breast cancer patients. Breast Cancer Res Treat 2013; 138(3): 657-64.

[20] Buggy DJ, Smith G. Epidural anaesthesia and analgesia: better outcome after major surgery? Growing evidence suggests so. BMJ 1999; 319: 530-1.

[21] O'Riain SC, Buggy DJ, Kerin MJ, et al. Inhibition of the stress response to breast cancer surgery by regional anesthesia and analgesia does not affect vascular endothelial growth factor and prostaglandin E2. Anesth Analg 2005; 100: 244-9.

[22] Sultan SS. Paravertebral block can attenuate cytokine response when it replaces general anesthesia for cancer breast surgeries. Saudi J Anaesth 2013; 7(4): 373-7.

[23] Cuellar A, Ramos J, Flores G, et al. Comparison of two anesthetic techniques on the plasma level of inflammatory markers. Cir Ciruj 2007; 75: 99-105.

[24] Hadimioglu N, Ulugol H, Akbas H, et al. Combination of epidural anesthesia and general anesthesia attenuates stress response to renal transplantation surgery. Transplant Proc 2012; 44(10): 2949-54.

[25] Bar-Yosef S, Melamed R, Page GG, et al. Attenuation of the tumor-promoting effect of surgery by spinal blockade in rats. Anesthesiology 2001; 94: 1066-73.

[26] Exadaktylos AK, Buggy DJ, Moriarty DC, et al. Can anesthetic technique for primary breast cancer surgery affect recurrence or metastasis? Anesthesiology 2006; 105: 660-4.

[27] Rodriguez MA, Gonzalo IA, Alvarez EV, et al. Thoracic epidural anesthesia attenuates CRP levels in patients undergoing elective coronary artery bypass graft surgery with cardiopulmonary bypass. Minerva Anestesiol 2008; 74: 6619-26.

[28] Wedad M, Zaki K, Haleem M. The effect of addition of wound infiltration with local anaesthetic to interpleural block on postthoracotomy pain, pulmonary function and stress response in comparison to epidural and paravertebral block. Eg J Anaesth 2004; 20: 67-72.

[29] Ibrahim A, Mamdouh N. Comparison between continuous thoracic epidural block and continuous thoracic paravertebral block for thoracotomy pain relief. Ain Shams J Anesth 2009; 2: 16-26.

[30] Aggo AT, Fyneface-Ogan S, Mato CN. The differential impact of two anesthetic techniques on cortisol levels in Nigerian surgical patients. Nigerian J Clin Pract 2012; 15: 68-74. 